\title{
PSIKOEDUKASI PERILAKU ONLINE BERESIKO BAGI REMAJA
}

\author{
Zulfa Febriani ${ }^{1)}$, Melok Roro Kinanthi ${ }^{2)}$, Octaviani I. Ranakusuma ${ }^{3)}$ \\ zulfa.febriani@yarsi.ac.id ${ }^{1)}$, melok.roro@yarsi.ac.id ${ }^{2)}$, octaviani@yarsi.ac.id ${ }^{3)}$ \\ Fakultas Psikologi, Universitas YARSI ${ }^{1,2), 3)}$
}

\begin{abstract}
ABSTRAK
Pemanfaatan internet untuk jejaring sosial di kalangan remaja sangat tinggi. Hal ini membuka kesempatan remaja terpapar pada aktivitas online beresiko yaitu tersebarnya informasi personal, berinteraksi dengan orang yang tidak dikenal, aktivitas membuka, memposting atau mendapat kiriman konten yang berkaitan dengan seksual. Penulis memberi psikoedukasi yang bertujuan meningkatkan pemahaman dan kesadaran tentang aktivitas online beresiko kepada 18 remaja daerah Cempaka Putih Barat yang berusia 12-15 tahun. Peserta diberikan pemahaman mengenai apa itu internet, manfaat dan kerugiannya secara fisik dan mental, serta tips menggunakan internet secara sehat dan aman. Ada peningkatan pengetahuan mengenai penggunaan internet yang sehat dan aman namun tidak signifikan (uji Wilcoxon $=8, \mathrm{p}=.076$ ). Meskipun demikian, peserta merasa kegiatan tersebut bermanfaat. Saran untuk kegiatan selanjutnya adalah agar menjangkau kelompok usia remaja yang lebih luas dan memperjelas tampilan ilustrasi dari materi. Kegiatan juga dapat dilakukan dalam lingkungan sekolah.
\end{abstract}

Kata Kunci: perilaku online beresiko, internet, remaja.

\section{PENDAHULUAN}

\section{Latar Belakang}

Hasil penelitian Kementrian Kominfo bersama UNICEF pada tahun 2014 menunjukkan bahwa sekitar 30 juta anak dan remaja di Indonesia menggunakan internet dan lebih dari setengahnya mengakses melalui ponsel pribadi (Broto, Februari 2014). Hal ini perlu menjadi perhatian karena internet dapat memberikan manfaat sekaligus memiliki dampak negatif terhadap remaja.

Internet dapat berguna bagi remaja untuk mengakses informasi yang dibutuhkan untuk menyelesaikan tugas sekolah. Selain itu, internet juga dapat membantu remaja mengembangkan pergaulannya dengan mem-posting atau memperoleh foto dan informasi personal. Namun, penggunaan internet untuk konteks sosial ini dapat menyebabkan remaja terpapar pada aktiviitas online 
beresiko seperti mendapatkan informasi, gambar, tayangan, atau diminta melakukan sesuatu yang memuat pesan seksual (Noll, Shenk, Barnes, \& Haralson, 2013; Baumgartner, Vokenburg, \& Peter, 2010; Houck, Barker, Rizza, Hancock, Norton, \& Brown, 2014). Dampak berkelanjutan dari aktivitas ini adalah memengaruhi sikap permisif remaja secara seksual dan menguatkan belief yang salah mengenai aktivitas seksual (Zilmann dalam Braun-Courville \& Rojas, 2009).

Remaja biasanya sangat dipengaruhi oleh sikap kelompok pertemanannya. Mereka yang belum memiliki pengetahuan yang cukup biasanya berusaha memenuhi rasa ingin tahu melalui penyebaran informasi dalam kelompok pertemanannya tersebut walau informasi yang diperoleh bukan fakta yang shahih. Penulis mendapatkan informasi dari beberapa guru BK bahwa siswa sekolah biasanya sangat mengikuti perkembangan informasi yang tersebar melalui media sosial. Bahkan mereka meng-update status dengan gambar-gambar yang berkaitan dengan kehidupan personal mereka. Ada peristiwa di mana siswa meng-uppdate video kemesraan dia bersama pasangan dan disebarkan ke teman-temannya. Hal ini tentunya menjadi hal yang perlu mendapatkan perhatian karena berkaitan dengan etika dan harga diri remaja tersebut ke depannya.

Menurut informasi PPKS dari Sudin PPAPP Jakarta Pusat, pengetahuan mengenai perilaku internet beresiko ini sangat diperlukan dan dapat diberikan pada remaja baik di sekolah atau pun remaja di kalangan masyarakat pada umumnya terutama untuk mencegah dampak negatif akibat aktivitas online pada kesehatan mental remaja. Oleh karena itu, penulis berkordinasi dengan PPKS Sudin PPAPP Jakarta Pusat dan Forum Remaja (FORAJA) Cempaka Putih dalam memberikan edukasi mengenai kesadaran dan pemahaman tentang aktivitas internet beresiko pada remaja.

Berdasarkan analisis situasi di atas, upaya telah dilakukan guru di sekolah dengan memberikan larangan dan nasihat. Orang tua tidak sepenuhnya dapat mengontrol remaja dalam menggunakan internet. Belum adanya pemahaman dan kesadaran dari diri remaja itu sendiri mengenai dampak penggunaan intenet beresiko membuat hal ini lebih sulit dicegah. Oleh karena itu, penulis memberikan 
psikoedukasi untuk meningkatkan kesadaran dan pemahaman remaja mengenai dampak penggunaan internet beresiko.

\section{Tinjauan Pustaka}

Perilaku internet beresiko menurut Berson dan Berson (dalam Paluckaite dan Zardeckaite-Matulaitiene, 2016) merupakan aktivitas online atau tindakan yang berbahaya dan menyebabkan ancaman terhadap penggunanya. Ancaman ini menurut Ybarra dkk. (dalam Paluckaite dan Zardeckaite-Matulaitiene, 2016) dapat berupa masalah fisik, sosial, maupun psikologis. Perilaku online beresiko ini termasuk serangkaian pengalaman yang disengaja atau tidak disengaja, termasuk paparan pornografi, muatan online kebencian, rasis, kekerasan atau menyakiti, kontak yang tidak sesuai dan berpotensi bahaya melalui pelecehan atau perilaku menarik perhatian, dan tindakan mencari perhatian dengan perilaku bermasalah seperti bullying antar teman, melanggar privasi, dan sebagainya (Liau, dkk., Livingstone \& Haddon, Ybarra, dalam Livingstone \& Helsper, 2009). Livingstone, Haddon, Gorzig, dan Olafsson, (2011) menyimpulkan kemudian bahwa perilaku online beresiko ini yaitu perilaku beresiko seksual /paparan pornografi, berkomunikasi dengan orang yang tidak dikenal, membagi informasi pribadi, cyberbullying, dan mengakses situs atau halaman yang tidak sesuai dengan usia.

Livingstone dan Haddon (2009) menyatakan bahwa perilaku online beresiko yang terkait konten seksual merupakan yang terbanyak kedua setelah memberikan informasi personal. Perilaku online beresiko berikutnya adalah konten kebencian dan kekerasan, bullying disertai menerima komentar secara seksual/ yang tidak dikehendaki, dan yang terakhir adalah melakukan pertemuan langsung dengan teman yang dikenal melalui online. Tingginya keterlibatan remaja terkait perilaku online beresiko seksual dan berbagi informasi personal berkaitan dengan perubahan biopsikososial dan pubertas yang sedang dialami remaja, khususnya remaja usia akhir (Gamez-Guadix, Borrajo, \& Almendous, dalam Paluckaite dan Zardeckaite-Matulaitiene, 2016). Masa pubertas ini pun diiringi dengan kecenderungan remaja untuk bereksperimen dan mencari tahu mengenai identitas 
diri dan lingkungannya (Dowell, Burgess, \& Cavanaugh, dalam Paluckaite dan Zardeckaite-Matulaitiene, 2016; Santrock, 2015).

Beberapa cara yang dapat dilakukan untuk mencegah resiko perilaku online adalah melalui parental mediation, yaitu bagaimana orang tua mengatur hubungan antara anak dengan media, termasuk membatasi, mengajak berbicara, memantau aktivitas, dan membuat aturan mengenai penggunaan media (Nathanson; Volkenburg, Krcmar, Peeters \& Merseille; Kerr \& Stattin; dan Austin, dalam Livingstone \& Helsper, 2008). Pendekatan tersebut ada 5 dimensi yaitu: active mediation of internet use yang mana orang tua hadir atau berada di dekat anak serta mendorong anak untuk berbagi atau mendiskusikan aktivitas internet; active mediation of internet safety yang mana orang tua membimbing anak menggunakan internet secara aman, membantu atau mendiskusikan cara menghadapi kesulitan dalam berinternet; restrictive mediaton yang mana orang tua menentukan aturan dan batasan bagi anak dalam penggunaan internet; monitoring yang mana orang tua mengawasi jejak penggunaan internet anak; dan technical mediation yang mana orang tua menggunakan program atau pengaturan orang tua dalam menyaring, membatasi atau memantau anak dalam penggunaan internet (Livingstone, Haddon, Gorzig, \& Olafsson, 2010).

Selain menlalui parental mediation, menghindari resiko perilaku online juga dapat dilakukan dengan meningkatkan internet literacy, yaitu kemampuan untuk mengakses, menganalisa, mengevaluasi, dan membuat konten online (Livingstone \& Helsper, 2009). Menurut Buckingham (dalam Livingstone \& Helsper, 2009), memperoleh keterampilan untuk mengakses konten internet membantu pengguna untuk menganalisa konten yang dihasilkan oleh orag lain yang mana keterampilan kritis ini mendorong pengguna untuk membuat konten mereka sendiri. Untuk dapat membuat konten sendiri, otomatis pengguna akan mempelajari teknik dan perangkat konten.

\section{Tujuan dan Manfaat Kegiatan}

Tujuan dari kegiatan ini adalah agar remaja yang tergabung dalam Foraja kelurahan Cempaka Putih mendapatkan pemahaman dan menyadari dampak penggunaan internet beresiko. 
Kegiatan ini diharapkan dapat bermanfaat bagi remaja untuk lebih waspada dalam penyebaran informasi personal melalui internet dan menyampaikannya ke kawan terdekatnya agar juga meminimalisasi dampak negatif penggunaan internet.

\section{METODE}

Peserta dalam kegiatan ini adalah remaja berusia 12-15 tahun berjumlah 18 orang di daerah Cempaka Putih Barat. Metode yang penulis pilih dalam pelaksanaan kegiatan ini adalah psikoedukasi dan diskusi. Adapun topik-topik yang diangkat dalam materi adalah mengenai: Pengertian internet dan macam aktivitas yang dapat dilakukan; hal-hal positif dan negatif yang dapat terjadi melalui internet; dampak internet secara kesehatan fisik dan mental disertai ilustrasi mengenai mekanisme kerja syaraf dan otak ketika distimulasi dengan penggunaan internet yang mengakibatkan adiksi internet; dan tips dan trik menggunakan internet yang sehat dan aman. Berdasarkan teori parental mediation dan internet literacy yang telah dipaparkan di bagian tinjauan pustaka, maka penulis membagi materi mengenai tips berinternet sehat ini menjadi dua bagian, yaitu berkaitan dengan penggunaan dan berkaitan dengan interaksi. Pada bagian keamanan penggunaan, penulis menjelaskan mengenai batasan penggunaan internet dan setting keamanan secara umum. Pada bagian keamanan berinteraksi, penulis menjelaskan hal-hal yang perlu dilakukan ketika berinteraksi, memberi

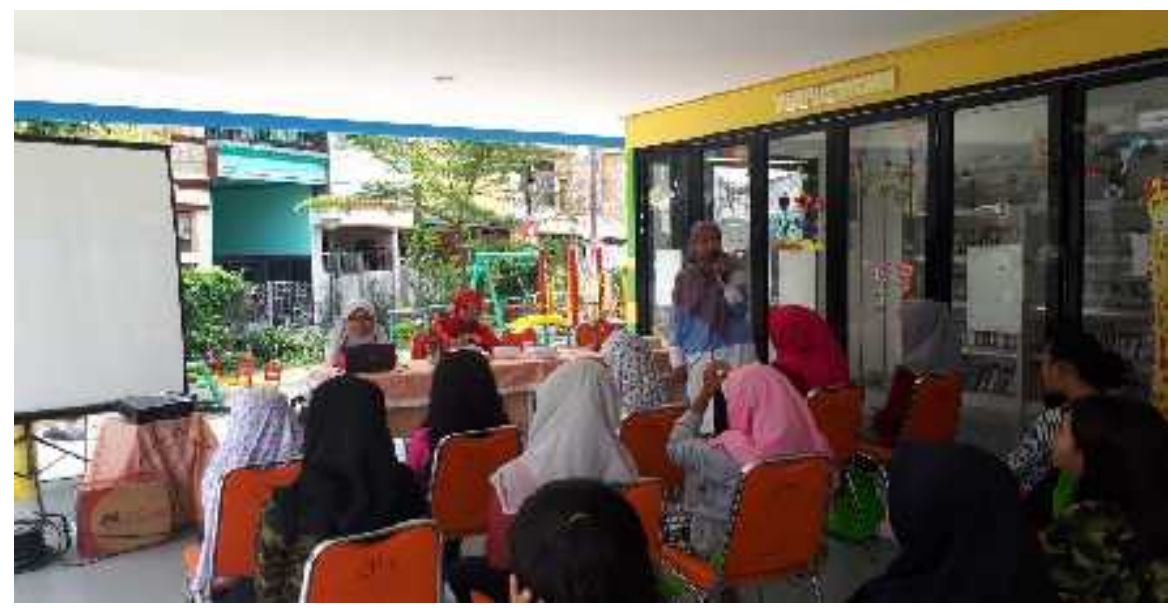

Gambar 1. Sesi materi tentang pengertian internet dan macam aktivitas yang dapat dilakukan; hal-hal positif dan negatif yang dapat terjadi melalui internet 
komentar, memposting gambar atau video.

Dalam menampilkan materi, penulis menyertakan power point yang diilengkapi gambar dan cuplikan video yang berkaitan dengan materi yang penulis

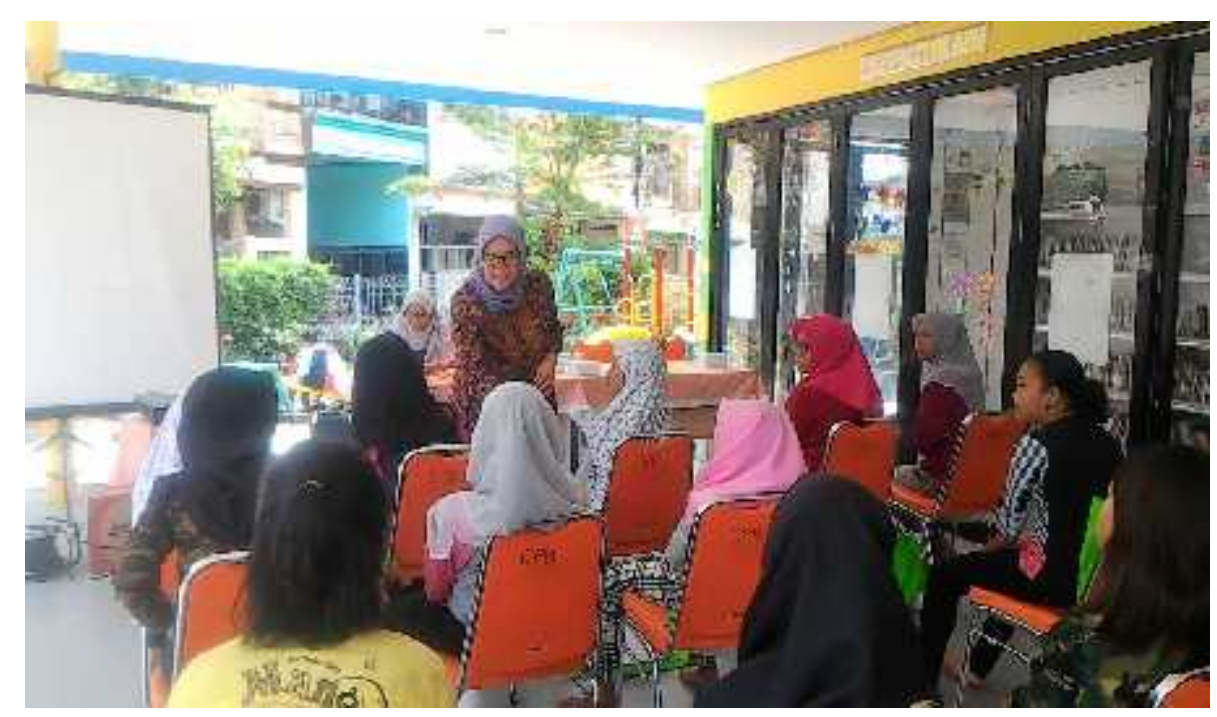

Gambar 2. Sesi materi tentang dampak internet secara fisik dan mental.

bawakan. Peserta juga diberikan materi tercetak agar dapat dibawa pulang dan dibaca kembali.

Untuk mengetahui keberhasilan program, maka evaluasi yang dilakukan adalah evaluasi efektivitas kegiatan yang mencakup tentang pengetahuan dan kesadaran remaja tentang aktivitas internet beresiko. Penulis memberikan soal berjumlah 13 dengan pilihan jawaban betul-salah sebagai pre-test dan post-test. Selain itu, penulis juga melakukan evaluasi pelaksanaan kegiatan berisi mengenai tanggapan peserta tentang keahlian pembawa materi, kebermanfaatan materi, waktu, sarana dan prasarana yang diberikan, serta saran.

\section{HASIL DAN PEMBAHASAN}

\section{Hasil Edukasi Perilaku Online Beresiko}

Penulis menggunakan pre-posttest dengan format pilihan jawaban betul salah untuk mengukur perubahan kognitif yang dialami peserta sebelum dan setelah menerima edukasi. Adapun muatan pre-posttest yang diberikan mengenai fakta penggunaan internet, dampak penggunaan internet dan keamanan 
penggunaan internet. Pertanyaan berjumlah 13 soal dan 2 pertanyaan lainnya berkaitan dengan persepsi peserta sendiri berkaitan dengan pengaturan keamanan berinternet.

Hasil pre-posttest aspek pengetahuan mengalami peningkatan antara pretest dengan posttest yang mana nilai posttest $(\mathrm{M}=7.714)$ lebih tinggi dibandingkan pretest $(\mathrm{M}=7.333)$. Meskipun demikian, ketika dibandingkan dengan uji statistic Wilcoxon, perbedaan antara pretest dengan posttest tidak signifikan $(\mathrm{W}=8, \mathrm{p}=.076)$. Psikoedukasi perilaku online tidak menunjukkan perubahan pengetahuan yang cukup berarti bagi peserta. Tabel 1 di bawah ini menunjukkan statistik data yang diperoleh.

Tabel 1. Statistik perbedaan pretest dan posttest

\begin{tabular}{ccccccc}
\hline Variabel & N & Nilai Min & Nilai Max & Mean & Std.Dev & Uji Beda \\
\hline Pretest & 15 & 7 & 8 & 7.333 & 0.488 & $\mathrm{~W}=8$ \\
Posttest & 14 & 6 & 11 & 7.714 & 1.204 & $\mathrm{P}=.076$ \\
\hline
\end{tabular}

Penulis juga melakukan evaluasi terhadap pelaksanaan kegiatan psikoedukasi perilaku onlibe beresiko bagi remaja ini. Skala penilaian berkisar antara 1 untuk kategori sangat tidak puas hingga 4 untuk kategori sangat puas. Secara umum, peserta merasakan kepuasan dalam kegiatan psikoedukasi perilaku online beresiko bagi remaja. Hal ini tampak dari nilai rata-rata peserta pada tiap aspek kegiatan berada pada $\geq 3$ (puas) pada tabel 2 .

Tabel 2. Evaluasi pelaksanaan kegiatan

\begin{tabular}{lcccccc}
\hline & $\begin{array}{c}\text { Penguasaan } \\
\text { materi }\end{array}$ & $\begin{array}{c}\text { Penjelasan } \\
\text { Mudah } \\
\text { dipahami }\end{array}$ & $\begin{array}{c}\text { Kesempatan } \\
\text { bertanya }\end{array}$ & $\begin{array}{c}\text { Manfaat } \\
\text { kegiatan }\end{array}$ & Waktu & $\begin{array}{c}\text { Sarana- } \\
\text { prasarana }\end{array}$ \\
\hline Valid & 14 & 14 & 14 & 14 & 14 & 14 \\
Missing & 2 & 2 & 2 & 2 & 2 & 2 \\
Mean & 3.357 & 3.071 & 3.214 & 3.071 & 3.429 & 3.357 \\
Std. Deviation & 0.4972 & 0.8287 & 0.699 & 0.615 & 0.646 & 0.497 \\
Minimum & 3.000 & 2.000 & 2.000 & 2.000 & 2.000 & 3.000 \\
Maximum & 4.000 & 4.000 & 4.000 & 4.000 & 4.000 & 4.000 \\
\hline
\end{tabular}

\section{Pembahasan}

Kegiatan psikoedukasi perilaku online beresiko ini bertujuan agar remaja Cempaka Putih Barat memperoleh pengetahuan dan menyadari bahaya 
penggunaan internet. Hasil evaluasi pre-posttest menunjukkan adanya penambahan pengetahuan meskipun tidak signifikan karena peningkatannya kecil.

Hasil pre-posttest dapat menunjukkan hasil yang tidak signifikan dapat disebabkan oleh jumlah partisipan yang kecil dan mengalami penyusutan jumlah yang mengisi kuesioner. Selain itu, dari hasil pretest-posttest menunjukkan pada dasarnya pengetahuan peserta mengenai perilaku online beresiko sudah cukup memadai. Hal ini dapat dilihat dari nilai rata-rata peserta saat pretest berada pada angka 7 dari total 13 aitem yang diberikan. Artinya, rata-rata peserta memiliki pengetahuan di atas $50 \%$ dari soal-soal yang ditanyakan.

Meskipun secara umum peserta memiliki pengetahuan yang cukup memadai, evaluasi pengetahuan peserta mengenai perilaku online beresiko ini juga perlu diperhatikan. Hal ini dikarenakan pada saat mengerjakan pre-posttest, kebanyakan peserta mengerjakan dengan membahasnya bersama teman, bahkan ada yang menanyakan jawabannya kepada teman. Padahal, tim telah mengingatkan sejak awal bahwa mereka diharapkan berkerja sendiri sesuai dengan apa yang mereka ketahui. Selain itu, model evaluasi betul-salah untuk mengukur pengetahuan mereka dapat menjadi salah satu metode yang lemah karena peserta dapat saja menjawab dengan benar secara kebetulan. Secara kualitatif, peserta pada dasarnya telah memiliki pengetahuan yang sederhana mengenai resiko atau bahaya perilaku online, seperti boros pulsa, mengganggu waktu belajar, kurang istirahat, jadi korban penipuan. Namun mereka belum mengetahui bahaya-bahaya lain yang tidak disadari seperti mengganggu emosi, kemampuan berpikir, penyalahgunaan internet untuk kenalan dan kencan dan pelecehan seksual, agresi atau kekerasan yang hal-hal tersebut merupakan resiko penggunaan internet (Liau, dkk., Livingstone \& Haddon, Ybarra, dalam Livingstone \& Helsper, 2009). Mereka juga memiliki sedikit pengetahuan bahwa perlu mengatur setting keamanan dalam menggunakan ponsel untuk berinternet. Namun mereka baru mengetahui kalau ada situs yang dapat dianggap cukup aman dengan melihat alamat telaahnya dan mengapa program dan aplikasi perlu diupdate secara berkala. Penulis juga memberikan saran terkait mengenai bagaimana mereka berinteraksi melalui internet dengan teman ataupun orang yang 
tidak dikenal. Hal-hal ini termasuk dalam aspek mediation of internet safety dan technical use (Livingstone, Haddon, Gorzig, \& Olafsson, 2010)

Secara pelaksanaan, meskipun berjalan tidak sesuai dengan yang direncanakan, hasil evaluasi pelaksanaan kegiatan menunjukkan tingkat kepuasan yang baik. Rata-rata hasil evaluasi berada dalam kategori memuaskan dengan penilaian tertinggi berada pada waktu pelaksanaan dan berikutnya pada penguasaan materi dari pembicaran seta sarana dan prasarana yang menunjang pelaksanaan kegiatan. Evaluasi dengan nilai terendah, meskipun masih memuaskan berada pada kategori penjelasan yang mudah dipahami dan manfaat kegiatan yang dirasakan peserta.

Penulis menyadari dari sisi materi memang memerlukan perhatian yang cukup baik karena ada beberapa materi yang menjelaskan mengenai mekanisme syaraf pusat dan istilah-istilah dalam penggunaan internet. Penulis telah berusaha memberikan ilustrasi melalui gambar dan film berkaitan dengan penjelasan mekanisme syafar pusat ketika terdampak dari internet serta gambar-gambar dalam hal pengaturan keamanan internet. Sayangnya, layar LCD yang digunakan kurang didukung dengan pencahayaan yang baik di ruangan RPTRA yang terbuka sehingga terlihat kurang jelas. Penulis meminta peserta untuk memenuhi tampat duduk di bagian depan untuk dapat melihat dengan lebih jelas.

\section{KESIMPULAN DAN SARAN}

Psikoedukasi perilaku online beresiko tidak menunjukkan peningkatan pengetahuan yang signifikan bila diukur secara kuantitatif. Faktor yang dapat berkontribusi antara lain adalah jumlah peserta yang sedikit, cara peserta menjawab, dan model evaluasi yang digunakan. Namun secara kualitatif, banyak pengetahuan baru yang diperoleh peserta mengenai perilaku online beresiko seperti macam resiko yang dapat dihadapi, bagaimana cara menghindari dan membatasi lebih lanjut resiko tersebut, bagaimana pengaruhnya ke sistem syaraf dan otak serta kesehatan secara fisik dan mental.

Saran bila akan diadakah kegiatan yang serupa adalah menjangkau remaja dari berbagai usia dengan jumlah yang lebih besar. Memastikan setting ruangan 
yang nyaman untuk menampilkan ilustrasi materi. Selain itu, kegiatan juga dapat dilaksanakan bekerja sama dengan institusi pendidikan dan menyesuaikan dengan permasalahan yang dihadapi di institusi tersebut berkaitan dengan penggunaan internet pada siswa.

\section{DAFTAR PUSTAKA}

Baumgartner, S.E., Valkenburg, P.M., \& Peter, J. (2010). Unwanted online sexual solicitation and risky sexual online behavior across the lifespan. Journal of Applied Developmental Psychology, Vol. 31, 439-447.

Braun-Courville, D.K \& Rojas, M. (2009). Exposure to sexually explicit web sites and adolescent sexual attitude and behaviors. Journal of Adolescent Health, $45,156-162$.

Broto, G.S.D. (2014). Riset Kominfo dan UNICEF Mengenai Perilaku Anak dan Remaja Dalam Menggunakan Internet. Diakses dari https://kominfo.go.id/index.php/content/detail/3834/Siaran+Pers+No.+17PIH-KOMINFO-2-

2014+tentang+Riset+Kominfo+dan+UNICEF+Mengenai+Perilaku+Anak+ dan+Remaja+Dalam+Menggunakan+Internet+/0/siaran_pers.

Houck, C.D., Barker, D., Rizza, C., Hancock, E., Norton, A., \& Brown, L.K. (2014). Sexting and sexual behavior in at-risk adolescents. Pediatrics, Vol. 133, (2), e276-e282.

Livingatome, S. \& Haddon, L. (2009). EU Kids Online and EU Kids Online II. Zeitschrift fur Psychologie (Horizons), 217 (4), 4-7.

Livingstone, S., Haddon, L., Gorzig, A., \& Olafssom, K. (2010). Risk and safety for children on the internet: The UK report. Full Finding from EU Kids Online Survey of UK 9-16 Year Olds and Their Parents. http://eprints.lse.ac.uk

Livingstone, S. \& Helsper, E.J. (2008). Parental mediation of children's internet use. Journal of Broadcasting and Electronic Media, vol. 52 (4), 581-599, DOI:10.1080/08838150802437396. Noll, J.G., Shenk., C.E., Barnes, J.E., \& Haralson, K.J. (2013). Association of maltreatment with high-risk internet behaviors and offline encounters. Pediatrics, Vol. 131 (2), e510e517.

Paluckaite, U. \& Zardeckaite-Matulaitine, K. (2016). Students' engagement in risky online behavior: The comparison of youth and secondary schools. The European Proceedings of Social and Behavioral Sciences. 
www.researchgate.net

Santrock, J.W. (2015). Life-span development, $15^{\text {th }}$ ed. USA : McGraw-Hil Education. 